\title{
Test anxiety and emotion regulation among undergraduate medical students in China: the mediating role of psychological resilience
}

Yquguo Liu

Guangdong Medical University

Haiyan Pan

Guangdong Medical University

Runhuang Yang

Guangdong Medical University

Xingjie Wang

Guangdong Medical University

Jiawei Rao

Guangdong Medical University

Xingshan Zhang

Guangdong Medical University

Congcong Pan ( $\nabla$ pcc@gdmu.edu.cn )

Guangdong Medical University

Primary research

Keywords: Psychological resilience, Test anxiety, Emotion regulation, Medical student

Posted Date: June 1st, 2020

DOI: https://doi.org/10.21203/rs.3.rs-31326/v1

License: (a) This work is licensed under a Creative Commons Attribution 4.0 International License.

Read Full License 
1 Test anxiety and emotion regulation among undergraduate medical students in

2 China: the mediating role of psychological resilience

3

4

5

6

7

8

9

10

11

12

13

14

15

16

17

18

19

20

21

22

23

24

25

26

27

28

29

30

31

32

33

34

35

36

37

38

39

40

41

42

43

44

45

Yuguo Liu ${ }^{\dagger}$, Haiyan Pan ${ }^{\dagger}$, Runhuang Yang, Xingjie Wang, Jiawei Rao, Xingshan Zhang and Congcong Pan*

School of Public Health, Guangdong Medical University, Dongguan, China;

* Correspondence: pcc@gdmu.edu.cn.

† These authors contributed equally to this work.

(1)

(1)

5

7
1 


\section{Abstract}

Background: Medical students experience a considerable amount of anxiety due to exams. Emotion regulation and psychological resilience are established protective factors of individual mental health, however, the investigations for the effects of anxiety were limited. The goal of the present study was to examine the relationship of psychological resilience and emotion regulation with test anxiety and the associated factors of them among medical students.

Methods: In this cross-sectional survey, a simple random sampling methods was used to select the participants. Information from a sample of 1266 medical students was collected by self-reporting questionnaires. Logistic regression was applied to test the associations between test anxiety and emotion regulation, resilience. Bootstrap were conducted to explore the mediating role of resilience.

Results: Our important results were that the prevalence of problematic test anxiety among medical students to be $71.4 \%, 33.7 \%$ was high test anxiety. Gender and academic performance correlated significantly with test anxiety, emotion regulation, and psychological resilience. There were correlations between test anxiety and various dimensions of emotion regulation and psychological resilience $(P<0.01)$. Emotion regulation and psychological resilience predicted emerging test anxiety. The mediating role of psychological resilience was identified for the effects of emotion regulation on test anxiety.

Conclusions: Findings suggest that emotion regulation affected test anxiety through psychological resilience, which may provide insights for clinical psychologists, raise their awareness of the importance of cultivating and improving medical students' psychological resilience, and prompt them to offer psychological support to students with test anxiety as early as possible. The 
combination of curing and self-healing can solve the root cause of the problem and truly apply psychological research to improving the mental health of the general public.

Keywords: Psychological resilience, Test anxiety, Emotion regulation, Medical student

\section{Background}

Test anxiety is considered as a set of psychological responses (such as worry, stress, emotionality) that individual experience negative consequences or failure of an exam or similar evaluation situation [1]. It can occur at any phase of exam. According to educational psychologists and experts in education, an average level of anxiety is useful as an effective motivational factor can enhance one's performance for more effort [2]. While for some, taking high-stakes exams has a significant influence on the emotional and physiological well-being of exam-takers, it may arouse feelings of fear, incompetence or even anger in others [3-4]. From 2001 to 2011, the proportion of students with test anxiety in China increased from $21.8 \%$ to $27.52 \%$. Interestingly, students majoring in medicine generally have higher level of test anxiety than students of other majors. This is mainly attributed to the fact that medical students are demanding to master a large amount of knowledge, clinical practice skill and professional quality tests. Therefore, it is practical significance to study the prevalence of test anxiety in medical students.

Emotion regulation is defined as "the process by which we influence which emotions we have, when we have them, and how we experience and express them" [8]. Among the emotion regulation strategies researched in the field, cognitive reappraisal and expressive suppression emerged as two widely-investigated strategies associated with physical health, mental health, and social well-being [9-11]. Cognitive reappraisal refers to the process involving a reinterpretation of the meaning of an emotional stimulus and subsequently, leading to a change of the initial 
trajectory of an emotional response [8]. In contrast, expressive suppression is a response- focused emotion regulation strategy whereby people adjust their emotional experience by suppressing the expression of that emotional state [10]. Previous studies suggested that cognitive reappraisal was view as an adaptive emotion regulation strategy [10,12-13]. For example, cognitive reappraisal was found to reduce negative emotions and heighten positive ones, thereby enhancing mental health and interpersonal functioning. Compared to cognitive reappraisal, expressive suppression potentially prevents the suppressors from experiencing positive emotions, increases experiences of negative emotions, and creates a sense of inauthenticity, which are detrimental to mental and physical health [14-15].

Studies have shown that cognitive reappraisal and expressive suppression are closely associated with anxiety. Cognitive reappraisal can regulate individual anxiety to promote his/her mental flexibility and emotional well-being [16], while negative emotion regulation is closely associated with individual negative emotions, especially anxiety. The anxiety level of adolescents depends on the use of cognitive reappraisal strategy, with less use of cognitive reappraisal associated with higher anxiety level [17]. Therefore, cognitive reappraisal is an important but difficult strategy for anxious individuals.

Psychological resilience refers to the ability of an individual to effectively adapt to and cope with frustrations, difficulties, or adversities, and maintain mental health [18]. Studies have found that psychological resilience can alleviate the impact of stress on anxiety [19], and individuals with high psychological resilience have faster cardiovascular recovery from negative emotional arousal and higher levels of positive emotions [20]. A large number of longitudinal studies have shown a significant correlation between positive emotions and psychological resilience [21-23]. 
115 Meanwhile, psychological resilience, as a positive psychological quality, may be an important

116 regulating variable in the face of stress. Studies have shown that psychological resilience can be 117 used to predict anxiety [24].

118 Studies have found that cognitive reappraisal strategy is associated with high anxiety level

119 while expressive suppression strategy is associated with low anxiety level [25-26]. However, most

120 of these studies did not involve other variables, making it impossible to determine whether the

121 above relationship between emotion regulation strategies and anxiety would change with the

122 addition of other variables. Emotion regulation and psychological resilience are protective factors

123 of individual mental health; they are closely related [21-23] and may have a joint effect on anxiety.

124 Based on literature analysis and current research gaps, we aimed to analyze the relationship of

125 psychological resilience and emotion regulation with test anxiety among a large sample of medical

126 students in China, and hypothesized as follows: psychological resilience and emotion regulation

127 are associated with test anxiety and accurately predict it, and psychological resilience may play a

128 mediating role in the effect of emotion regulation on test anxiety.

129

Methods

131

\section{Study population and procedure}

Totally 1300 undergraduate students at a Chinese medical university in Guangdong were selected with simple random sampling methods. Of these students were eligible to participate and written consent was obtained before the study began. This was an cross-sectional survey performed from June to December, 2019. The study was approved by the Ethics Committee of the Guangdong Medical University (ref. YJYS2019027). Face-to-face interview was applied to inform notes then 
provide responses on the questionnaires. Concerning acute anxiety evoked during period of stress was shown to be worse than usual, we decided on the exam period at the end of the first and second semesters during this year for the present study [27].

\section{Measures}

Test anxiety

For measuring the students' test anxiety, the Chinese adaptation of Sarason's Test Anxiety Scale (TAS) was used $[1,28]$. TAS consists of 37 items to which respondents are asked to report how often they experience anxiety symptoms before, during, and after taking tests. The responses are included "Yes" and "No". The "yes" responses are added one point up and "no" 0 point, except six items are reversed (e.g., the 3rd, 15th, 26th, 27th, 29th, 33th). Respondents were classified as three different levels of test anxiety according to TAS score. Scores falling at or below 12 were indicative of low-test anxiety, scores falling above 12 and below 20 were indicative of a normal level of anxiety, score falling at or above 20 were indicative of high level of test anxiety. The Cronbach's alpha was alpha of .77 , split-half reliability of .60 in a Chinese sample [28]. The Cronbach's $\alpha$ of TAS in this sample was 0.884 , indicates an acceptable level of internal consistency.

\section{Emotion Regulation}

Cognitive reappraisal and expressive suppression frequency during a student's daily life was measured by Emotion Regulation Questionnaire (ERQ), which developed by Gross and John [29]. It includes 14 items that describe five universal emotions (including disgust, anger, sadness, fear and joy) that involve regulating expression, and it can be divided into 2 dimensions: cognitive reappraisa scale includes 6 items, and the expressive suppression scale includes 4 items. Items are assessed on a 7-point Likert scale ranging from 1(strongly disagree) to 7 (strongly agree). The 
total score range from 14 to 98 ; with higher scores indicate a higher frequency in using a particular emotion regulation strategy. Previous studies demonstrated ERQ as a reliable tool with Cronbach's alpha coefficient of .83 for cognitive reappraisal, and 0.77 for expressive suppression. Current research yielded that the Chinese version of this scale has adequate reliability and validity [30]. The Cronbach's $\alpha$ of ERQ in our study was 0.903 .

\section{Resilience}

For the assessment of students' psychological resilience, the Chinese adaptation of Connor-Davidson Resilience Scale (CDRS) was used [31, 32]. The CDRS, developed by Connor and Davidson [33], measures the capability to deal with adversity and stress. Based on exploratory factor analysis of the designer, the 25 items of CDRS can be grouped into 3 dimensions: strength, optimism, resilience. The respondents were expected to answer items based on their own situation. Each statement is rated on a 5-point scale ranging from 0 (not true at all) to 4 (true nearly all the time). The combined score of CDRS ranges from 0 to 100, with a higher sum indicates a greater resilience. The scale was found to be internally consistent and reliable as indicated by the alpha coefficient value 0.89 [34]. Evidence suggests that the CDRS is a very reliable scale which was used by researchers to find out level of psychological resilience among Chinese college students [31-32]. In our sample, the internal consistency of CDRS was very high (Cronbach's alpha $=$ 0.955).

\section{Statistical analysis}

All statistical data were imported to SPSS version 21.0 (SPSS Inc., USA) for analysis. The categorical variables were presented with frequencies and proportions while the continuous variables were described by means and standard deviations (SDs). Associated factors of test anxiety, resilience and emotion regulation were examined by using $t$-tests and ANOVA, 
187

188

respectively. Comparisons the correlation between emotion regulation, resilience and test anxiety were performed via correlation analyses and the predictor of test anxiety were analyzed by regression analyses. Bootstrapping was conducted in testing mediation effects. A $p$-value was less than 0.05 was considered statistically significant.

\section{Results}

\section{General characteristics of participants}

The final sample consisted of 1266 participants for further analysis, because of missing information in critical items. The valid response rate was 96.6\%. Major characteristics of study subjects were listed in Table 1. Of these participants, females hold the predominant majority $(N=820,64.8 \%)$. There were 991 participants $(78.3 \%)$ that took 5 to 7 exams, as the predominant majority. Students reported engaged in part-time jobs or member acount for $26.5 \%, 83.9 \%$, respectively. More than half of the participants $781(61.7 \%)$ came from town and most of the respondents were not single-child family $971(76.7 \%)$ and regarding education level of the respondent's majority of the participant were 1rd year 605(47.8\%) followed by 3nd year $312(24.6 \%)$. 
Table 1 Socio demographic characteristics of medical students

\begin{tabular}{llll}
\hline Variable & Category & Frequency & Percentage \\
\hline Gender & Male & 446 & 35.2 \\
Grade & Female & 820 & 64.8 \\
& First year & 605 & 47.8 \\
& Second year & 264 & 20.9 \\
& Third year & 312 & 24.6 \\
& Fourth year & 64 & 5.1 \\
Colleage & Fifth year & 21 & 1.7 \\
& Public health & 280 & 22.1 \\
& Humanities and management & 14 & 1.1 \\
& Clinical medicine & 100 & 7.9 \\
Part-time jobs & Medical technology & 234 & 18.5 \\
& Pharmacy & 638 & 50.4 \\
Members of the club & Yes & 335 & 26.5 \\
& No & 931 & 73.5 \\
Academic evaluation & No & 1062 & 83.9 \\
& Excellent & 204 & 16.1 \\
& Moderate & 351 & 27.7 \\
& Lower-moderate & 490 & 38.7 \\
Single-child family & Yes & 241 & 19.0 \\
& No & 184 & 14.5 \\
Examination number & Below 5 & 82 & 6.5 \\
& 5 to 7 & 991 & 78.3 \\
& 8 to 9 & 144 & 11.4 \\
& Above 9 & 49 & 3.9 \\
& City & 485 & 38.3 \\
& Country & 781 & 61.7 \\
& Nes & 295.3 \\
& 971 & 76.7 \\
\hline
\end{tabular}

212

\section{Levels and associated factors of test anxiety, resilience and emotion regulation}

214 As seen in Table 2, more than half (71.4\%) of medical students had problematic test anxiety, 33.7\%

215 was high test anxiety. The average scores of the three specific dimensions of psychological

216 resilience varied, ranging from $9.07 \pm 2.70$ (optimism) to $29.68 \pm 8.557$ (resilience). Regarding

217 emotion regulation, cognitive reappraisal $(34.30 \pm 6.824)$ adopted by students was higher than

218 expressive suppression $(30.26 \pm 7.046)$.

219 Moreover, we found gender and academic performance were significantly associated with among test anxiety, psychological resilience and emotion regulation. In other words, the odds of

221 having positive test anxiety, psychological resilience and emotion regulation for those who have 
222 excellent academic evaluation is higher than those who have poor academic evaluation.

223 Additionally, female reported more difficulties in above-mentioned three aspects compared to

224 male.

225 Table 2 Means, standard deviations, and correlations

\begin{tabular}{|c|c|c|c|c|c|c|c|c|c|}
\hline Variable & & $\begin{array}{l}\text { Psychologica } \\
1 \text { resilience }\end{array}$ & Resilience & Strength & Optimism & $\begin{array}{l}\text { Emotion } \\
\text { regulation }\end{array}$ & $\begin{array}{l}\text { Cognitive } \\
\text { reappraisal }\end{array}$ & $\begin{array}{l}\text { Expressive } \\
\text { suppression }\end{array}$ & $\begin{array}{l}\text { Test } \\
\text { anxiety }\end{array}$ \\
\hline Total & & $58.89 \pm 15.28$ & $29.68 \pm 8.56$ & $20.14 \pm 5.01$ & $9.07 \pm 2.70$ & $64.56 \pm 11.92$ & $34.30 \pm 6.82$ & $30.26 \pm 6.82$ & $16.75 \pm 7.62$ \\
\hline \multirow[t]{3}{*}{ Gender } & Male & $60.96 \pm 17.58$ & $30.99 \pm 9.85$ & $20.64 \pm 5.71$ & $9.33 \pm 2.97$ & $65.52 \pm 13.93$ & $33.97 \pm 7.72$ & $31.55 \pm 7.63$ & $15.77 \pm 7.74$ \\
\hline & Female & $57.77 \pm 13.76$ & $28.97 \pm 7.68$ & $19.86 \pm 4.56$ & $8.93 \pm 2.53$ & $64.03 \pm 10.63$ & $33.48 \pm 6.28$ & $29.55 \pm 7.61$ & $17.27 \pm 7.51$ \\
\hline & $T$ & $3.33 * *$ & $3.75^{* * *}$ & $2.49 *$ & $2.39 *$ & $1.97 *$ & -1.184 & $4.66 * * *$ & $-3.36 * *$ \\
\hline \multirow[t]{4}{*}{ Grade } & First year & $59.87 \pm 15.31$ & $30.19 \pm 8.61$ & $20.45 \pm 4.97$ & $9.22 \pm 2.69$ & $64.42 \pm 11.99$ & $34.22 \pm 6.88$ & $30.20 \pm 7.25$ & $16.61 \pm 7.61$ \\
\hline & Second- year & $59.59 \pm 16.70$ & $30.36 \pm 9.09$ & $20.10 \pm 5.47$ & $9.13 \pm 2.92$ & $64.91 \pm 12.54$ & $34.26 \pm 6.88$ & $30.65 \pm 7.17$ & $16.74 \pm 7.74$ \\
\hline & Third year & $56.26 \pm 13.83$ & $28.10 \pm 7.83$ & $19.43 \pm 4.69$ & $8.73 \pm 2.52$ & $64.54 \pm 11.45$ & $34.35 \pm 6.69$ & $30.19 \pm 6.61$ & $17.02 \pm 7.74$ \\
\hline & $F$ & $3.17 *$ & $3.80 * *$ & $2.38 *$ & 1.18 & 0.26 & 0.14 & 0.81 & 0.17 \\
\hline \multirow{5}{*}{$\begin{array}{l}\text { Academic ev } \\
\text { aluation }\end{array}$} & Excellent & $61.89 \pm 13.41$ & $31.22 \pm 7.59$ & $21.26 \pm 4.48$ & $9.40 \pm 2.46$ & $65.89 \pm 11.08$ & $35.28 \pm 6.21$ & $30.61 \pm 6.81$ & $15.49 \pm 6.67$ \\
\hline & Moderate & $60.22 \pm 14.41$ & $30.37 \pm 8.14$ & $20.56 \pm 4.61$ & $9.29 \pm 2.67$ & $64.76 \pm 11.46$ & $34.55 \pm 6.57$ & $30.21 \pm 7.00$ & $16.51 \pm 7.61$ \\
\hline & Lower-moderate & $56.40 \pm 14.73$ & $28.37 \pm 8.23$ & $19.27 \pm 4.90$ & $8.77 \pm 2.58$ & $63.46 \pm 11.67$ & $33.55 \pm 6.96$ & $29.91 \pm 6.61$ & $16.85 \pm 7.94$ \\
\hline & Poor & $52.92 \pm 19.11$ & $26.64 \pm 10.62$ & $18.00 \pm 6.17$ & $8.28 \pm 3.15$ & $62.92 \pm 14.47$ & $32.75 \pm 8.01$ & $30.17 \pm 8.12$ & $19.64 \pm 8.22$ \\
\hline & $F$ & $17.93 * * *$ & $15.01 * * *$ & $21.73 * * *$ & $9.22 * * *$ & $3.37 *$ & $6.86 * * *$ & 0.51 & $12.48 * * *$ \\
\hline \multirow{3}{*}{$\begin{array}{l}\text { Single-chil } \\
\text { d family }\end{array}$} & Yes & $59.37 \pm 16.45$ & $29.94 \pm 9.14$ & $20.19 \pm 5.35$ & $9.24 \pm 2.85$ & $64.01 \pm 12.75$ & $33.49 \pm 7.16$ & $30.52 \pm 7.41$ & $17.12 \pm 7.88$ \\
\hline & No & $58.75 \pm 14.92$ & $29.61 \pm 8.37$ & $20.12 \pm 4.90$ & $9.02 \pm 2.65$ & $64.73 \pm 11.65$ & $34.54 \pm 6.70$ & $30.18 \pm 6.93$ & $16.63 \pm 7.54$ \\
\hline & $T$ & 0.58 & 0.58 & 0.21 & 1.21 & -0.90 & $-2.32 *$ & 0.72 & 0.95 \\
\hline \multirow{3}{*}{$\begin{array}{l}\text { Part-time } \\
\text { jobs }\end{array}$} & Yes & $60.71 \pm 15.44$ & $30.84 \pm 8.72$ & $20.52 \pm 5.02$ & $9.35 \pm 2.75$ & $66.00 \pm 12.75$ & $34.90 \pm 6.97$ & $31.10 \pm 7.30$ & $16.37 \pm 7.97$ \\
\hline & No & $58.24 \pm 15.18$ & $29.26 \pm 8.46$ & $20.00 \pm 5.00$ & $8.98 \pm 2.68$ & $64.04 \pm 11.56$ & $34.08 \pm 6.76$ & $29.95 \pm 6.93$ & $16.88 \pm 7.49$ \\
\hline & $T$ & $2.54 *$ & $2.91 * *$ & 1.62 & $2.18 *$ & $2.59 *$ & 1.88 & $2.56^{*}$ & -1.05 \\
\hline \multirow{3}{*}{$\begin{array}{l}\text { Members } \\
\text { of the club }\end{array}$} & Yes & $59.26 \pm 14.79$ & $29.86 \pm 8.26$ & $20.27 \pm 4.88$ & $9.12 \pm 2.65$ & $64.68 \pm 11.59$ & $34.46 \pm 6.67$ & $30.22 \pm 6.94$ & $16.86 \pm 7.55$ \\
\hline & No & $57.00 \pm 17.53$ & $28.74 \pm 9.91$ & $19.42 \pm 5.60$ & $8.84 \pm 2.93$ & $63.92 \pm 13.49$ & $33.47 \pm 7.53$ & $30.45 \pm 7.59$ & $16.17 \pm 7.97$ \\
\hline & $T$ & 1.73 & 1.53 & $2.03 *$ & 1.34 & 0.83 & 1.90 & -0.43 & 1.18 \\
\hline \multirow[t]{3}{*}{ Birthplace } & City & $59.32 \pm 15.94$ & $29.86 \pm 8.84$ & $20.17 \pm 5.23$ & $9.29 \pm 2.82$ & $64.74 \pm 12.27$ & $34.09 \pm 6.78$ & $30.66 \pm 7.34$ & $17.41 \pm 7.87$ \\
\hline & Country & $58.63 \pm 14.87$ & $29.57 \pm 8.38$ & $20.12 \pm 4.87$ & $8.94 \pm 2.62$ & $64.44 \pm 11.70$ & $34.43 \pm 6.85$ & $30.01 \pm 6.85$ & $16.33 \pm 7.44$ \\
\hline & $T$ & 0.78 & 0.57 & 0.18 & $2.23 *$ & 0.44 & -0.87 & 1.58 & $2.46^{*}$ \\
\hline
\end{tabular}

227 Correlation between study variables

228 To that extent we performed spearman rank correlation analyses between test anxiety, resilience 
and emotion regulation. This correlation was shown in Table 3. As expected, test anxiety has a significant negative correlation with resilience $(\mathrm{r}=-0.382, p<0.01)$ and emotion regulation $(\mathrm{r}=$ $-0.158, p<0.01)$. A low level of test anxiety is linked with a high degree of resilience as well as emotion regulation in medical students. Interesting, more than emotion regulation and resilience,

233 all the dimensions of that were significantly negative correlations with test anxiety respectively.

234 Table 3 The correlation coefficients for the test anxiety, emotion regulation and resilience $(\mathrm{N}=231)$

Variable

(1)

(2)

(3)

(4)

(5)

(6)

(7)

(8)

(1)Test anxiety

(2)Emotion regulation

$-0.158 * *-$

(3)Cognitive reappraisal

$-0.191 * * \quad 0.854 * * \quad-$

(4)Expressive suppression

$-0.082 * * \quad 0.864 * * \quad 0.476 * * \quad-$

(5)Resilience

$\begin{array}{llll}-0.382 * * & 0.507 * * & 0.559 * * & 0.316 * *\end{array}$

(6)Resilience

$\begin{array}{lllll}-0.374 * * & 0.500 * * & 0.537 * * & 0.326 * * & 0.972 * *\end{array}$

(7)Strength

$\begin{array}{llllll}-0.364 * * & 0.492 * * & 0.562 * * & 0.288 * * & 0.946 * * & 0.867 * *\end{array}$

(8)Optimism $-0.304 * * \quad 0.371 *$

$* P<0.05, \quad * * P<0.01, * * * P<0.001$

\section{Testing the mediating role of resilience}

We finally set out to investigate whether resilience was a mediator. Multiple regression analysis showed that cognitive reappraisal negatively predicted test anxiety $(\beta=-0.191, p<0.01)$. Similarly, resilience and strength negatively predicted test anxiety $(\beta=-0.235, p<0.01 ; \beta=-0.160, p<0.01$, respectively). Table 4 indicates the unstandardized parameter estimates and standard errors in the model. It can be assumed that practial work aimed at developing the cognitive reappraisal and resilience could effectively ensure less test anxiety.

Furthermore, regression analyses found that dimensions of resilience possible be taken as mediating role. Total effects model was conducted by taking cognitive reappraisal as independent variable $\mathrm{X}$, resilience and strength as mediating variables $\mathrm{M} 1$ and $\mathrm{M} 2$, and test anxiety as dependent variables $Y$ to examine the mediating role of resilience. Bootstrapping was conducted 
to test the mediating effects, as it can yield more accurate estimates of the indirect effect standard errors than alternative approaches to testing mediation [35]. We adopt Bootstrapping to test mediation effects and the $95 \%$ confidence interval (CI) based on 5000 bootstrap samples with replacement. When the indirect effects as represented here by confidence intervals, did not include zeros, we can infer that mediation occurred. The results presented that, $a b$ was statistically significant. Therefore, there was a mediation occurred of resilience and strength on emotion regulation and test anxiety. In other words, the path model going from emotion regulation to resilience to test anxiety was significant. As shown in Table 5, the indirect effects of resilience and strength on emotion regulation and test anxiety did not include a zero (95\% CI: $-0.189,-0.091 ; 95 \%$ CI: $-0.162,-0.048$, respectively), thereby indicating resilience and strength as a mediator. Moreover, controlling for mediating variables, the direct effects of cognitive reappraisal on test anxiety include a 0 (95\% CI: $-0.027,0.112)$. It indicated that resilience and strength performanced a completely mediating role in the relation between emotion regulation and test anxiety.

Table 4 The regression analyses for the test anxiety, emotion regulation and resilience $(\mathrm{N}=231)$

\begin{tabular}{|c|c|c|c|c|c|c|c|c|c|}
\hline \multirow{2}{*}{$\begin{array}{l}\text { Independent } \\
\text { variable }\end{array}$} & \multicolumn{4}{|c|}{ Equation 1 (dependent variables: test anxiety) } & \multicolumn{5}{|c|}{ Equation 2 (dependent variables: test anxiety) } \\
\hline & $\mathrm{B}^{*}$ & $\mathrm{SE}^{*}$ & $\beta^{*}$ & $t$ & $\mathrm{~B}$ & $\mathrm{SE}$ & $\beta$ & $t$ & \\
\hline Constant & 24.046 & 1.079 & & $22.290 * * *$ & 27.879 & 0.821 & & $33.941 *$ & \\
\hline $\begin{array}{l}\text { Cognitive } \\
\text { reappraisal }\end{array}$ & -0.213 & 0.031 & -0.191 & $-6.900 * * *$ & & & & & \\
\hline Resilience & & & & & -0.209 & 0.046 & -0.235 & $-4.506^{*}=$ & \\
\hline Strength & & & & & -0.244 & 0.079 & -0.160 & -3.078 & \\
\hline $\mathrm{R}^{2^{*}}$ & & & & 0.036 & & & & 0.146 & \\
\hline $\mathrm{F}$ & & & & $47.611 * * *$ & & & & 108.230 & \\
\hline $\begin{array}{l}{ }^{*} \mathrm{~B}=\text { regressio } \\
\text { coefficient of }\end{array}$ & $\begin{array}{l}\text { coefficient, } \\
\text { determination }\end{array}$ & $\mathrm{SE}=$ & standard & errors, $\beta=$ & standar & dized & regression c & efficient, & $\mathrm{R}^{2}=$ \\
\hline
\end{tabular}




\begin{tabular}{lllll}
\hline Roadmap & Category & Effect ratio & $\begin{array}{l}\text { 95\% CI } \\
(\text { lower, upper) }\end{array}$ & $\begin{array}{l}\text { Relative mediation } \\
\text { effect }(\%)\end{array}$ \\
\hline Cognitive reappraisal $\rightarrow$ Test anxiety & Total effect & -0.213 & $-0.273,-0.152$ & $100 \%$ \\
Cognitive reappraisal $\rightarrow$ Test anxiety & direct effect & 0.043 & $-0.027,0.112$ & $14.40 \%$ \\
Cognitive reappraisal $\rightarrow$ Resilience $\rightarrow$ Test anxiety & indirect effect & -0.146 & $-0.189,-0.091$ & $48.76 \%$ \\
Cognitive reappraisal $\rightarrow$ Strength $\rightarrow$ Test anxiety & & -0.110 & $-0.162,-0.048$ & $36.84 \%$ \\
\hline
\end{tabular}

271

272

273

274

\section{Discussion}

The population characteristics of medical students' test anxiety, emotion regulation, and psychological resilience

Findings from the present study demonstrated that the prevalence of high test anxiety among medical students to be $33.7 \%$, higher than $32.64 \%$ in that of 2015 . Literature shows that the magnitude of high test anxiety for students was $27.52 \%$ in 2015 [5], for $21.8 \%$ college students in 2001 [28]. Our results thus confirm previous reports showing that the odds of developing test anxiety was higher among medical students as compared to other majors in China [6-7]. The possible reasons are described as follows. From the perspective of the knowledge to be mastered, medical students have to take many abstract and difficult major courses. Meanwhile, they cannot just make up the number in class since their future careers are related to human life, and medical schools have very strict requirements for their academic performance. From the perspective of employment pressure, the employment situation is not optimistic for medical students. Practicing medicine requires extremely high professional skills, which makes it impossible to find a job in a highly-ranked hospital without adequate professional skills. At present, the demand from society for technical personnel has increased dramatically. Compared with the theoretical knowledge acquired in school, practical skills acquired at work are more important for engineering students.

Moreover, we found that more than half of the medical students $(71.4 \%)$ had problematic test anxiety. The result of the current study was higher than the study conducted at USA (55\%). This 
difference may be due to the variations in several factors that have an impact on anxiety, such as curriculum evaluation methods, different requirements about students' physical ability and other factors. Universities in the US adopt flexible teaching and performance assessment methods, with a focus on the improvement of students' self-efficacy. Universities in China generally adopt a single final examination with formatted content for the evaluation of academic performance [36, 37].

Our study results demonstrate that test anxiety, resilience and emotion regulation are closely associated with both academic performance and genders. As the research data show, female students have higher levels of test anxiety while male students represent a higher level of resilience as well as emotion regulation. With regard to gender differences, most researchers report higher levels of test anxiety in females [38, 39]. This may be attributed to the fact that women are under the pressure from society to develop their own competitiveness. In addition, some scholars have shown that women use negative cognitive emotion regulation strategies more often than men [40]. Parents usually teach boys to control emotions, which makes boys have higher expectations for their ability to control emotions. When encountering emotional problems, men tend to be resilient and finally master the skills to control emotions in silence. In contrast, women are likely to distract their attention owing to their emotional personality traits and psychological characteristics, and tend to adopt immature and negative coping styles when dealing with stressful events, which makes them inferior to men in emotional control and psychological resilience [41]. Students with poor academic performance suffer from more severe test anxiety and less emotion regulation and psychological resilience than those with moderate to excellent academic performance. 
314 This result is consistent with data from student samples in different countries. Researchers

315 reported that students with moderate to excellent academic performance had developed learning

316 abilities and strategies to easily cope with examinations. While some less capable students may

317 experience such expectations due to the unrealistic expectations of parents, peers, or teachers.

318 These expectations may increase their anxiety in exam situations and cause performance problems

320

regulation strategies, cognitive reappraisal, and expressive suppression among medical students.

This was slightly different from previous studies [10, 43, 44], which had relatively consistent results on cognitive reappraisal that cognitive reappraisal was an adaptive strategy. However, no consistent conclusion was reached in studies on expressive suppression. Some scholars believed that expressive suppression was not adaptive. Nevertheless, whether a strategy is good and adaptive depends on personal experience, scenarios, and personal goals. One-third of the students in this study showed relatively high levels of test anxiety. In high-intensity negative scenarios, individuals were more inclined to choose avoidance-oriented strategies such as expressive suppression, which had better effects in the short term. This was consistent with previous studies $[45,46,47]$ that subjects tended to adopt cognitive reappraisal strategy for low or moderate-intensity stimuli, and expressive suppression strategy in high-intensity negative scenarios. A correlation analysis showed that the coefficient of positive correlation between cognitive reappraisal and expressive suppression reached 0.476 , which means that medical students who were used to adopting the cognitive reappraisal may frequently adopt the expressive 
suppression, and the two strategies may coexist instead of contrast each other. However, subsequent regression analysis found that cognitive reappraisal had a direct negative predictive effect on test anxiety (cognitive reappraisal reduced test anxiety, while expressive suppression did not reduce test anxiety), which indicates that the function of cognitive reappraisal generally shows cross-cultural consistency and medical students can effectively reduce the negative stimuli and emotions such as test anxiety by managing their emotions with cognitive reappraisal. Interestingly, in terms of expressive suppression, studies with American, Australian, and Belgian college students as subjects found that $[48,49]$ the individuals were less likely to adopt expressive suppression to regulate positive emotions, and expressive suppression was associated with reduced positive emotions and psychological adaptation and increased negative emotions. However, in countries with Eastern cultures such as China [50], expressive suppression has a role in social adaptation and not necessarily has a direct negative impact on individual psychological adaptation. In the scenario of academic failure, college students in China would have reputation-based emotions (e.g., shame and embarrassment) and tended to cope with the emotions by themselves [51]. The results of this study exemplify the cross-cultural consistency of cognitive reappraisal adaptiveness and the cultural differences of expressive suppression.

According to the regression equation of data, According to the regression equation, cognitive reappraisal, resilience, and strength were negative predictors of test anxiety. This indicates that individuals with high levels of emotion regulation and psychological resilience can quickly recover from severe stress and danger and successfully response to corresponding changes, which were reflected in reduced test anxiety levels in this study. Meanwhile, we also found a significantly positive correlation between psychological resilience and emotion regulation 
strategies in the sampled medical students. This was consistent with previous studies conducted with a intervention was an effective method, by emotion regulation to enhance the psychological resilience of adolescents $[52,53]$. Due to the impact of positive psychology, a large number of studies have focused on the relationship between psychological resilience and positive emotions. Many studies agreed that individuals with high psychological resilience had higher levels of positive emotions than those with low psychological resilience. Individuals with high psychological resilience could use cognitive reappraisal to cultivate their positive emotions and effectively induce others to use positive emotion regulation, thus creating a supportive social environment for themselves. In later studies, researchers also focused on the relationship between negative emotion regulation and psychological resilience.

However, studies on the negative emotion levels of individuals with different levels of psychological resilience showed inconsistent results. Some scholars believed that there were no significant differences in negative emotion regulation between individuals with high and low psychological resilience [21], and other suggested that individuals with higher psychological resilience had lower levels of depression [54]. Ong [55] emphasized that individuals with high psychological resilience evoked positive emotions while experiencing negative emotions, but those with low psychological resilience only regulated negative emotion in adversity or emergencies. It can be seen that researchers' conclusions were divided on the relationship between psychological resilience and the level of negative emotions, which may be attributed to the different subject populations selected by researchers or the fact that there are numerous psychosociology factors that affect negative emotions. In our study, we found that individuals with higher psychological resilience had higher levels of emotion regulation, including cognitive 
reappraisal and expressive suppression, which was in agreement with several previous studies.

382

383

\section{The mediating role of psychological resilience}

One of the key findings of this study was that emotion regulation indirectly affected test anxiety through the mediating effect of psychological resilience. When medical students felt lower stability of emotion regulation, they would alleviate the impact of emotion regulation on test anxiety through the resilience and strength of psychological resilience. This reflected that the close relationship between emotion regulation and psychological resilience, and supported previous results that psychological resilience can buffer the crisis. Hence, psychological resilience as a positive psychological quality may be an important regulating variable in the face of stress. Bandura [56] pointed out that enhancing individual abilities through experience was the most reliable way to develop strong and resilient self-efficacy. College students with high psychological resilience were not defeated by negative emotions, making them more confident that they can effectively regulate their emotions. Therefore, compared with interfering with emotion regulation, strengthening frustration education and cultivating their psychological qualities such as resilience and strength to resist stress are more effective ways to reduce test anxiety and help medical students to adapt to campus and society in the long run.

\section{Conclusions}

Our empirical research suggests that gender and academic performance significantly affected medical students' test anxiety, emotion regulation, and psychological resilience. The test anxiety experienced by medical students would be reduced when their psychological resilience and emotion regulation increased, especially when their control of cognitive reappraisal, resilience, and strength was improved. Emotion regulation indirectly affected test anxiety through the 
mediating effect of psychological resilience. This may provide insight for clinical psychologists and raise awareness of the importance of cultivating and improving the psychological resilience of medical students. Investigation of the continuous psychological development of subjects was limited due to the cross-sectional study design. A deeper understanding of the background of the subject population and exclusion of irrelevant variables that may impair data reliability, such as environmental factors, are needed to improve the reliability of data in future research.

\section{List of abbreviations}

TAS: Test Anxiety Scale; ERQ: Emotion Regulation Questionnaire; CDRS: Connor-Davidson Resilience Scale; CI: confidence interval; SPSS: Statistical Software for Social Science

\section{Ethics approval and consent to participate}

The study was approved by the Ethics Committee of the Guangdong Medical University (ref. YJYS2019027). Written informed consent was obtained from all participants prior to the survey administration.

\section{Consent for publication}

Not applicable.

\section{Availability of data and materials}

The datasets analyzed during the current study are available from the corresponding author on reasonable request.

\section{Competing interests}

Authors declare no conflict of interests for this article.

\section{Funding}

This work is supported by the Social Science and Technology Development Project of Dongguan 
Provincial key platforms and major scientific research projects of Guangdong colleges and universities-(educational research) project (No. 2017GXJK062); Provincial key platforms and projects of Guangdong colleges (No. 2018KQNCX096); Key scientific research platforms and research projects of ordinary universities in Guangdong Province (No. 2018KQNCX088).

\section{Authors' contributions}

LYG conceived and designed the study, wrote the paper. WXJ, RJW and ZXS performed the investigation and carried out data collection. YRH and PHY contributed to analyze the data. LYG and PCC drafed and edited the manuscript. PHY reviewed the manuscript. All authors read and agreed to the published version of the manuscript.

\section{Acknowledgements}

We express our thanks to all study participants.

\section{References}

1. Sarason IG, Sarason BR. Test anxiety: Handbook of social and evaluation anxiety. New York: Plenum;1990.

2. Arbabisarjou A, Zare S, Shahrakipour M, Ghoreishinia G. Analyzing test anxiety among medical sciences students of Zahedan in 2015. Int J Med Res Health Sci. 2016;5(7):334-7.

3. Duan HX, Yuan YR, Yang C, Zhang L, Zhang K, Wu JH. Anticipatory processes under academic stress: An ERP study. Brain Cogn. 2015;94:60-7.

4. Dyrbye LN, Thomas MR, Shanafelt TD. Medical student distress: causes, consequences, and proposed solutions. Mayo Clin Proc. 2005;80(12):1613-22.

5. Chen R, Liu XN, Zhou RL. The attentional bias to threat stimuli in test-anxious students. Psychological Science. 2011;34(1):151-4.

6. Gu C, Liu SJ, Miao XH. Investigation and analysis of medical students' examination anxiety. China Higher Medical Education. 2007;(4):61-2.

7. Guo XX, Dong YY, Zhao XP, Li X, Zhang LX. Investigation on students' test anxiety in medical college. China Journal of Health Psychology. 2016;24(12):1877-80.

8. Gross JJ. Antecedent-and response-focused emotion regulation: divergent consequences for experience, expression, and physiology. J Pers Soc Psychol. 1998;74(1): 224-37.

9. Gross JJ, Richards JM, John OP. Emotion regulation in everyday life. In: Snyder DK, Simpson JA, Hughes JN, editors. Emotion regulation in couples and families: Pathways to 
dysfunction and health. Washington DC: American Psychological Association; 2006.p. 13-35.

10. Gross JJ, John OP. Individual differences in two emotion regulation processes: implications for affect, relationships, and well-being. J Pers Soc Psychol. 2003;85(2):348-62. https://doi.org/10.1037/0022-3514.85.2.348 PMID: 12916575

11. Brewer SK, Zahniser E, Conley CS. Longitudinal impacts of emotion regulation on emerging adults: variable- and person-centered approaches. J Appl Dev Psychol. 2016; 47:1-12.

12. Mauss IB, Cook CL, Cheng JY, Gross JJ. Individual differences in cognitive reappraisal: experiential and physiological responses to an anger provocation. Int J Psychophysiol. 2007; 66(2):116-124. https://doi.org/10.1016/j.ijpsycho.2007.03.017 PMID: 17543404

13. Goldin PR, Manber T, Hakimi S, Canli T, Gross JJ. Neural bases of social anxiety disorder: emotional reactivity and cognitive regulation during social and physical threat. Arch Gen Psychiatry. 2009;66(2):170-80.

14. Roberts NA, Levenson RW, Gross JJ. Cardiovascular costs of emotion suppression cross ethnic lines. Int J Psychophysiol. 2008;70(1):82-7.

15. Larsen JK, Vermulst AA, Eisinga R, English T, Gross JJ, Hofman E, Scholte RH, Engels RC. Social coping by masking parental support and peer victimization as mediators of the relationship between depressive symptoms and expressive suppression in adolescents. J Youth Adolesc. 2012;41(12):1628-42.

16. Gross JJ, Thompson R. Emotion regulation: Conceptual foundations. New York: Guilford; 2007.

17. Carthy T, Horesh N, Apter A, Edge MD, Gross JJ. Emotional reactivity and cognitive regulation in anxious children. Behav Res Ther. 2010;48(5):384-93.

18. Haeffel GJ, Vargas I. Resilience to depressive symptoms: the buffering effects of enhancing cognitive style and positive life events. J Behav Ther Exp Psychiatry. 2011;42(1):13-8.

19. Gloria CT, Steinhardt MA. Relationships among positive emotions, coping, resilience and mental health. Stress health. 2016;32(2):145-56.

20. Tugade MM, Fredrickson BL. Regulation of positive emotions: emotion regulation strategies that promote resilience. Journal of happiness studies. 2007;8(3):311-33.

21. Tugade MM, Fredrickson BL, Barrett LF. Psychological resilience and positive emotional granularity: examining the benefits of positive emotions on coping and health. J Pers. 2004; 72(6): 1162-90.

22. Moneta GB, Vulpe A, Rogaten J. Can positive affect "undo" negative affect? A longitudinal study of affect in studying. Personality and Individual Differences. 2012;53(4): 448-52.

23. Waugh CE, Thompson RJ, Gotlib IH. Flexible emotional responsiveness in trait resilience. Emotion. 2011; 11(5):1059-67.

24. Sudom KA, Lee JE, Zamorski MA. A longitudinal pilot study of resilience in Canadian military personnel. Stress Health. 2014;30(5):377-85.

25. Martin RC, Dahlen ER. Cognitive emotion regulation in the prediction of depression, anxiety, stress, and anger. Pers Individ Differ. 2005;39(7):1249-60.

26. Mcrae K, Heller SM, John OP, et al. Context-dependent emotion regulation: suppression and reappraisal at the burning man festival. Basic Appl Soc Psychol. 2011;33(4):346-50. 
27. Spielberger C, Gorsuch R, Lushene R. State-Trait Anxiety Inventory, Manual for the State-Trait Anxiety Inventory. Palo Alto: Consulting Psychologist Press; 1970.

28. Wang CK. Reliability and Validity of Test Anxiety Scale-Chinese Version. Chinese Mental Health J.2001;(2):96-7.

29. Gross JJ, John OP. Individual differences in two emotion regulation processes: implications for affect, relationships, and well-being. J Pers Soc Psychol. 2003;85(2):348-62. https://doi.org/10.1037/0022-3514.85.2.348 PMID: 12916575

30. Wang L, Liu HC, Du W, Li ZQ. Test of difficulties in emotion regulation scale in Chinese People. China J Health Psychology. 2007; (4):336-40.

31. Yu XN, Lau JT, Mak WW, Zhang J, Lui WW, Zhang J. Factor structure and psychometric properties of the Connor-Davidson Resilience Scale among Chinese adolescents. Compr Psychiatry. 2011; 52(2):218-24.

32. Yu X, Zhang J. Factor analysis and psychometric evaluation of the connor-davidson resilience scale with Chinese people. Social Behavior and Personality. 2007; 35(1): 19-30.

33. Connor KM. Davidson JR. Development of a new resilience scale: the Connor-Davidson Resilience Scale (CD-RISC). Depress Anxiety. 2003; 18(2): 76- 82.

34. Nishi D, Uehara R, Yoshikawa E, Sato G, Ito M, Matsuoka Y. Culturally sensitive and universal measure of resilience for Japanese populations: Tachikawa Resilience Scale in comparison with Resilience Scale 14-item version. Psychiatry Clin Neurosci. 2013; 67(3):174-81.

35. Shrout PE, Bolger N. Mediation in experimental and nonexperimental studies: new procedures and recommendations. Psychol Methods. 2002;7(4):422-45.

36. Guan X. International Comparison and Reference on Curriculum Evaluation in Universities - From the Perspective of Students' Value Experience. Higher Education of Sciences. 2017;(3):67-71. doi: 10.3969/j.issn.1000-4076.2017.03.010

37. Ji DD, Wang YX. The enlightenment of American college curriculum evaluation system on foreign language teaching in China - for Concordia University's Institute of Education. College forum. 2018;(29):15-6.

38. Afzal H, Afzal S, Siddique SA, Naqvi SA. Measures used by medical students to reduce test anxiety. J Pak Med Assoc. 2012;62(9):982-6.

39. Putwain D, Daly AL. Test anxiety prevalence and gender differences in a sample of English secondary school students. Educ Stud. 2014;40: 554-70.

40. Garnefski N, Teerds J, Kraaij V, Legerstee J, Van den Kommer T. Cognitive emotion regulation strategies and depressive symptoms: differences between males and females. Personality and Individual Differences. 2004; 36(2):267-76.

41. Brody LR. The socialization of gender differences in emotional expression: display rules, infant temperament, and differentiation. In: Fischer AH, editors. Gender and emotion: social psychological perspectives. London: Cambridge University Press; 2010. p. 24-47.

42. Wigfield A, Eccles JS. Test anxiety in elementary and secondary school students. Educ Psychol. 1989; 24:159-83.

43. Mauss IB, Cook CL, Cheng JY, Gross JJ. Individual differences in cognitive reappraisal: experiential and physiological responses to an anger provocation. Int J Psychophysiol. 2007; 66(2):116-24.

44. Goldin PR, Manber T, Hakimi S, Canli T, Gross JJ. Neural bases of social anxiety disorder: 
emotional reactivity and cognitive regulation during social and physical threat. Arch Gen Psychiatry. 2009; 66(2):170-80.

45. Sheppes G, Scheibe S, Suri G, Gross JJ. Emotion-regulation choice. Psychol Sci. 2011; 22(11):1391-6.

46. Sheppes G, Scheibe S, Suri G, Radu P, Blechert J, Gross JJ. Emotion regulation choice: a conceptual framework and supporting evidence. J Exp Psychol Gen. 2014; 143(1):163-81.

47. Hay AC, Sheppes G, Gross JJ, Gruber J. Choosing how to feel: emotion regulation choice in bipolar disorder. Emotion. 2015; 15(2):139-45.

48. Butler EA, Lee TL, Gross JJ. Emotion regulation and culture: are the social consequences of emotion suppression culture-specific? Emotion. 2007; 7(1):30-48.

49. Brans K, Koval P, Verduyn P, Lim YL, Kuppens P. The regulation of negative and positive affect in daily life. Emotion. 2013; 13(5):926-39.

50. Liu Y, Sang B, Gong SY, Ding XC, Pang TT. Cultural differences on function of emotional expression suppression. Advances in Psychological Science. 2016; 24(10):1647-54.

51. Mortenson ST. Cultural differences and similarities in seeking social support as a response to academic failure: A comparison of American and Chinese college students. Communication Education. 2006; 55(2):127-46.

52. Southwick SM, Charney DS. The science of resilience: implications for the prevention and treatment of depression. Science. 2012; 338(6103):79-82.

53. Wu G, Feder A, Cohen H, Kim JJ, Calderon S, Charney DS, Mathe AA. Understanding resilience. Front Behav Neurosci. 2013;7:10.

54. Bonanno GA, Galea S, Bucciarelli A, Vlahov D. What predicts psychological resilience after disaster? The role of demographics, resources, and life stress. J Consult Clin Psychol. 2007; 75(5):671-82.

55. Ong AD, Bergeman CS, Bisconti TL, Wallace KA. Psychological resilience, positive emotions, and successful adaptation to stress in later life. J Pers Soc Psychol. 2006; 91(4):730-49.

56. Bandura A, Caprara GV, Barbaranelli C, Gerbino M, Pastorelli C. Role of affective self-regulatory efficacy in diverse spheres of psychosocial functioning. Child Dev. 2003;74(3):769-82. 